\title{
Bitter melon (Momordica charantia) attenuates atherosclerosis in apo-E knock- out mice possibly through reducing triglyceride and anti-inflammation
}

\author{
Yanmei Zeng*, Meiping Guan, Chenzhong Li, Lingling Xu, Zhongji Zheng, Jimin Li and Yaoming Xue*
}

\begin{abstract}
Background: Bitter melon (BM, Momordica charantia) has been accepted as an effective complementary treatment of metabolic disorders such as diabetes, hypertension, dyslipidemia and etc. However it is unclear whether BM can prevent the progression of atherosclerosis. To confirm the effects of BM on atherosclerosis and explore its underlying mechanisms, we design this study.

Methods: Twenty four male apolipoprotein E knock-out (ApoE-/-) mice aged 8 weeks were randomly divided into control group fed with high fat diet (HFD) only and BM group fed with HFD mixed with 1.2\%w/w BM. After 16 weeks, body weight, food intake, blood glucose, serum lipids were measured and the atherosclerotic plaque area and its histological composition were analyzed. The expression of vascular cell adhesive molecules and inflammatory cytokines in the aortas were determined using quantitative polymerase chain reaction.

Results: Body weight gain and serum triglycerides (TG) significantly decreased in BM group. BM reduced not only the atherosclerotic plaque area and the contents of collagen fibers in atherosclerotic plaques but also the serum soluble vascular cell adhesion molecule (VCAM)-1 and P-selectin levels, as well as the expressions of monocyte chemoattractant protein (MCP)-1 and interleukin (IL)-6 in aortas.

Conclusion: Our study indicates that dietary BM can attenuate the development of atherosclerosis in ApoeE-/- mice possibly through reducing triglyceride and anti-inflammation mechanism.
\end{abstract}

Keywords: Bitter melon, Triglyceride, Atherosclerosis, Anti-inflammation

\section{Background}

Atherosclerosis is a chronic inflammatory response in arteries characterized by deposition of lipids, recruitment of monocytes, formation of macrophage foam cells, proliferation and migration of vascular smooth muscle cells (VSMCs) and endothelial dysfunction [1, 2]. Abundant evidences showed that Traditional Chinese Medicine (TCM) can present the progression of atherosclerosis via anti-oxidation and anti-inflammation [3-5]. The bioactive components of bitter melon, one of the most common TCMs, have been reported to improve the glucose and lipids metabolism,

\footnotetext{
*Correspondence: emilyzengym@163.com; xueyaoming999@126.com Department of Endocrinology and Metabolism, Nanfang Hospital, Southern Medical University, No.1838, Guangzhou Avenue, Guangzhou 510515, Guangdong, China
}

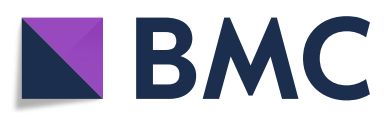

(c) The Author(s). 2018 Open Access This article is distributed under the terms of the Creative Commons Attribution 4.0 International License (http://creativecommons.org/licenses/by/4.0/), which permits unrestricted use, distribution, and reproduction in any medium, provided you give appropriate credit to the original author(s) and the source, provide a link to the Creative Commons license, and indicate if changes were made. The Creative Commons Public Domain Dedication waiver (http://creativecommons.org/publicdomain/zero/1.0/) applies to the data made available in this article, unless otherwise stated.

important risk factors of atherosclerosis, via anti-oxidation and anti-inflammation [6-9]. Furthermore, studies show that $\mathrm{BM}$ can regulate metabolism through the activation of peroxisome proliferator-activated receptor (PPAR) and AMP-activated protein kinase (AMPK) [10-16], which may represent protective mechanisms against atherosclerosis via potential anti-inflammation in endothelial cells $[17,18]$. Recently the fermented milk-soymilk supplemented with $\mathrm{M}$. charantia (one of the bitter melon ) was reported to have an anti-atherosclerotic activity by increasing superoxide dismutase (SOD) and total antioxidant status (TAS) activity in hyperlipidemic hamsters [19]. However, it is unclear whether $\mathrm{BM}$ itself can prevent the progression of atherosclerosis. In the present study, we investigated the effects of BM on the 
Table 1 Data on body weight, food intake, fasting blood glucose, and blood lipid profile

\begin{tabular}{llll}
\hline & Control & BM & $P$ value \\
\hline Daily Food intake(g/w) & $37.13 \pm 3.42$ & $36.79 \pm 3.62$ & $0.79(\mathrm{NS})$ \\
Body weight(g) pretrement & $18.02 \pm 1.05$ & $18.09 \pm 1.10$ & 0.87 (NS) \\
Body weight(g) & $32.73 \pm 1.43$ & $30.95 \pm 1.23^{\mathrm{b}}$ & 0.004 \\
Fasting blood-glucose(mg/dl) & $109.58 \pm 10.65$ & $119.03 \pm 10.82$ & 0.10 (NS) \\
TC(mg/dl) & $1211.02 \pm 163.79$ & $1281.16 \pm 123.93$ & $0.35(\mathrm{NS})$ \\
$\mathrm{TG}(\mathrm{mg} / \mathrm{dl})$ & $60.73 \pm 15.62$ & $41.04 \pm 11.72^{\mathrm{a}}$ & 0.013 \\
$\mathrm{HDL}(\mathrm{mg} / \mathrm{dl})$ & $52.78 \pm 5.25$ & $50.60 \pm 14.32$ & $0.69(\mathrm{NS})$ \\
$\mathrm{LDL}(\mathrm{mg} / \mathrm{dl})$ & $919.61 \pm 96.49$ & $917.92 \pm 70.75$ & $0.97(\mathrm{NS})$ \\
$\operatorname{VLDL}(\mathrm{mg} / \mathrm{dl})$ & $789.24 \pm 157.62$ & $876.07 \pm 78.52$ & $0.19(\mathrm{NS})$ \\
\hline
\end{tabular}

Table1 $T G$ as triglycerides, $H D L$ as high-density lipoprotein, $L D L$ as low-density lipoprotein and VLDL as very low-density lipoprotein. Values are expressed as mean $\pm \mathrm{SD} ; n=8-12$ per group; ${ }^{\mathrm{a}} \mathrm{p}<0.05,{ }^{\mathrm{b}} \mathrm{p}<0.01$; Control versus BM

development of atherosclerosis induced by HFD in ApoE-/mice and explored the potential mechanisms.

\section{Methods}

\section{Animals and diets}

ApoE-/- mice with the C57BL/6 genetic background provided by Joslin Diabetes Center, Harvard Medical School (Boston, MA, USA ) were breeding in a pathogen-free environment with a $12 \mathrm{~h}$ light/dark cycle with free access to food and water and performed according to institutional and governmental guidelines. A high-fat diet containing $21.8 \%$ fat providing $42 \%$ energy and $1.25 \%$ cholesterol was purchased from GDLAC (GDLMC, Guangzhou, China). Twenty four male mice aged 8 weeks were randomized into control group (HFD, $n=12$ ) fed with high fat diet (HFD) only and BM -treated group (BM, $n=12)$ fed with HFD mixed with BM at a dose of $1.2 \% \mathrm{w} / \mathrm{w}$ for 16 weeks, based on a previous study [20]..
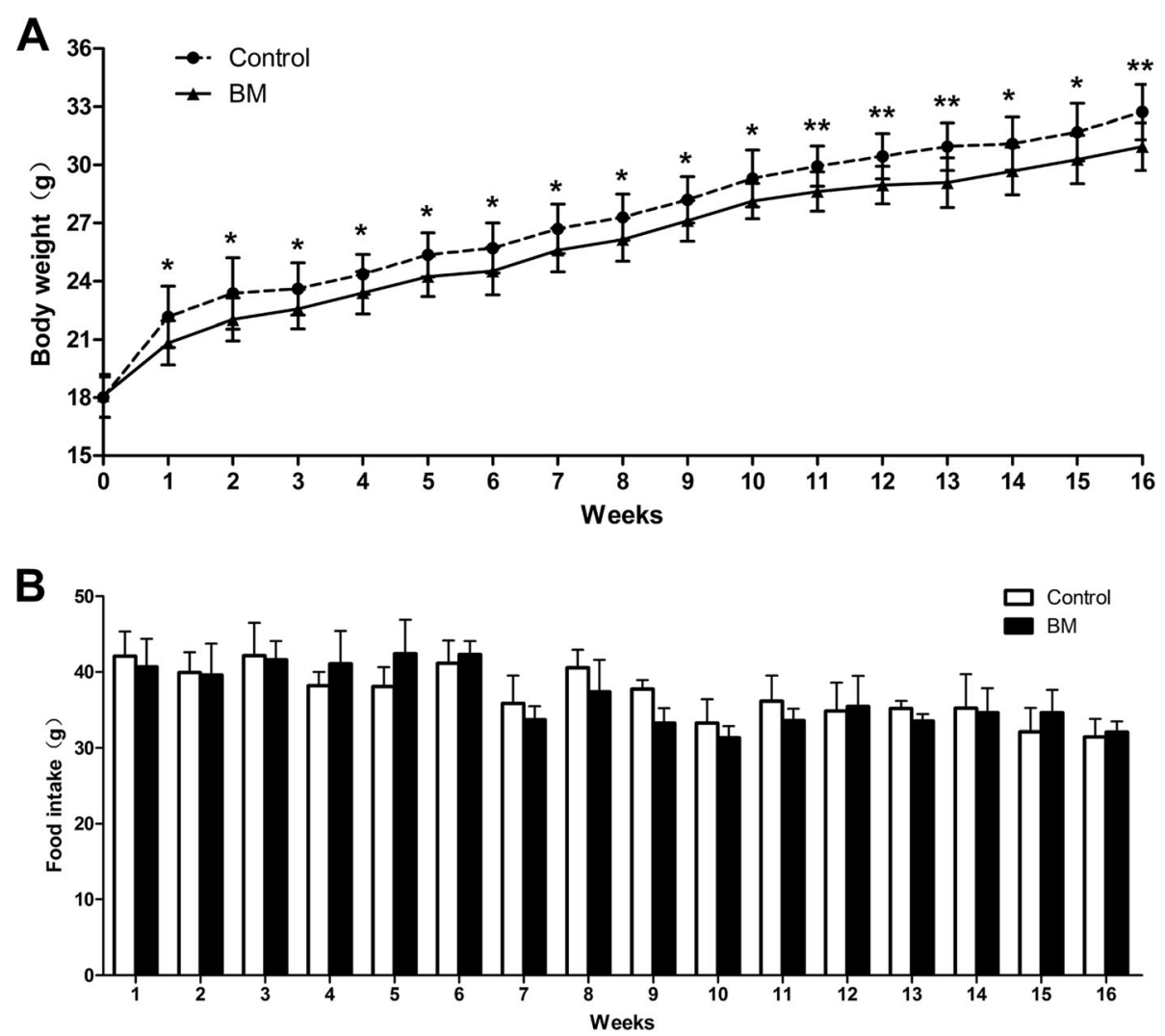

Fig. 1 Effects of BM on body weight and food intake in mice. a shows the body weight; (b) illustrates food intake in the two groups of mice; Data are presented as mean \pm SD, $n=8-12$ per group, Control vs BM. There is no differences in the body weight and food intake as well as blood glucose levels between the two groups 


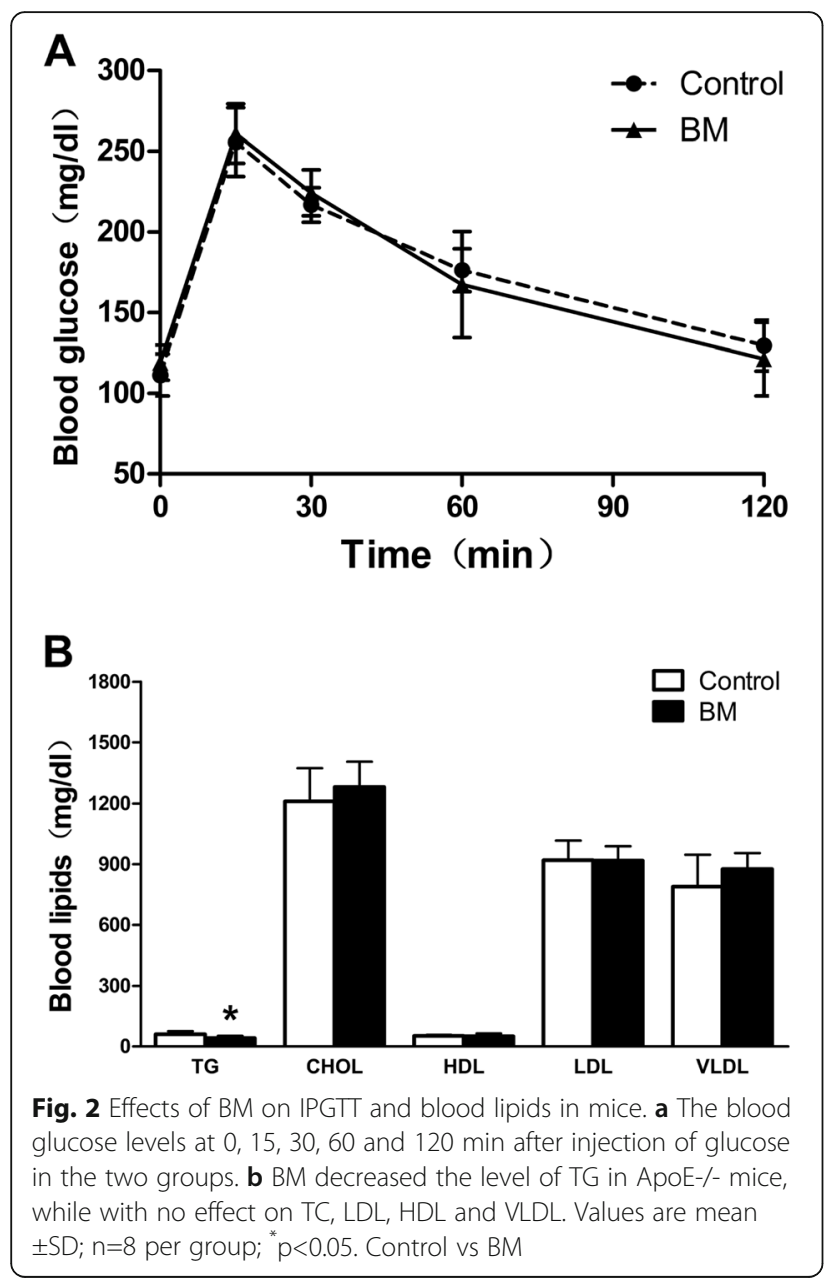

\section{Analysis of serum metabolic profile}

Body weight and food intake of animals were recorded weekly. Intraperitoneal glucose tolerance test (IPGTT), with injection of $20 \%$ glucose at a dose of $2 \mathrm{~g} / \mathrm{kg}$, was administered with tail vein blood at week 14 with One Touch Ultra meter (Lifescan; Johnson \& Johnson, USA) at $0,15,30,60$ and $120 \mathrm{~min}$. For the measurement of the blood lipids profile, blood was collected from orbital sinus of the animals which already fasting for 8 hours and anesthetized by isoflurane. We centrifuge the blood samples at $1500 \mathrm{~g} 4^{\circ} \mathrm{C}$ for $10 \mathrm{~min}$ to obtain the serums and store at $-80 \mathrm{oC}$. The measurement of the serum levels of TG, TC, LDL, HDL, VLDL are operated on BECKMAN AU-5800 automatic biochemical analyzer with Olympus original reagent, calibration and quality control solution(Olympus, Japan). Serum TG levels were measured by Glycerophosphate oxidase peroxidase (GPO-PAP) method. Serum TC levels were determined by the enzymatic method, HDL levels were determined by chemical modification method. LDL and VLDL levels were determined by selective lysis enzymatic method.
And the serum soluble adhesion molecules were determined by enzyme-linked immune-sorbent assay ( $R \& D$ Systems, UK). In addition, aortas and other tissues were collected at the end of the study and quickly frozen in liquid nitrogen and then stored at $-80^{\circ} \mathrm{C}$ for later analysis.

Quantification of atherosclerotic lesion area and measurements of atherosclerotic plaques histological composition

The aortas after opening and fixing in 10\% formalin for $36 \mathrm{~h}$ were stained with Sudan IV to detect the atherosclerotic lesion area and then photographed by a digital camera connected to a dissection microscope. The amount of atherosclerosis lesion was evaluated as the ratio of the atherosclerotic lesion area to the whole aorta area by Image-Pro Plus 6.0.

The aorta fixed in $10 \%$ formalin after $24 \mathrm{~h}$ was paraffin embedded and cross-sectioned to analyze its histological composition. Masson's trichrome stain kit (Maiwei, Xiamen, China) was used to assess the content of collagen fibers in atherosclerotic plaques and immune-histochemistry incubated with goat anti-macrophage-2 antigen (MAC-2) mouse macrophage or anti-alpha-smooth muscle cell ( $\alpha$-SMA) specific actin polyclonal antibody respectively (Bioss, Beijing, China) to qualify the contents of vascular smooth muscle cells and macrophage cells. All cross-sections were analyzed under an upright microscope (Nikon, Tokyo, Japan).The amounts of macrophage and smooth muscle cells as well as the collagen fibers were quantified by image-processing software (Image Pro-plus 6.0).

\section{Determination of Inflammatory cytokines mRNA levels in aortas}

The mRNA levels of MCP- 1 and IL- 6 were measured by SYBR Green Quantitative Real-time PCR. RNA were ed from aorta tissues with E.Z.N.A Total RNA Kit II (Omega, USA) and then reversed to cDNA with PrimeScript TM RT reagent Kit (Takara biotechnology, Dalian, China) under the following conditions: $37^{\circ} \mathrm{C}$ for $15 \mathrm{~min}, 85^{\circ} \mathrm{C}$ for 5 seconds and $4^{\circ} \mathrm{C}$ forever. Quantitative Real-time PCR was performed with ABI 7500 (ABI, USA) using SYBR premix Ex Taq (Takara biotechnology, Dalian, China) as follows: 1 cycle at $95^{\circ} \mathrm{C}$ for 30 minutes; 40 cycles at $95^{\circ} \mathrm{C}$ for 5 seconds and $60^{\circ} \mathrm{C}$ for 34 seconds; and 1 cycle $95^{\circ} \mathrm{C}$ for 15 seconds, $60^{\circ} \mathrm{C}$ for 1 minute and $95^{\circ} \mathrm{C}$ for $15 \mathrm{sec}$ onds. The primers used as follows: GAPDH F5'-GTG AAGCAGGCATCTGAGGG-3' and GAPDH R5'-CGAA GGTGGAAG AGTGGGAGT-3'; MCP-1 F5'-GCA GCA GGT GTC CCA AAG AA F-3' and MCP-1 R5'- ATT TAC GGG TCA ACT TCA CAT TCA A -3'; IL-6 F5'-AGG AGA CTT GCC TGG TGA AAA-3' and IL-6 R5'- AAA GCT GCG CAG AAT GAG ATG-3'. The relative quantification values for the mRNA expressions of MCP-1 and IL- 6 were calculated by $\Delta \Delta C \mathrm{~T}$. 
A

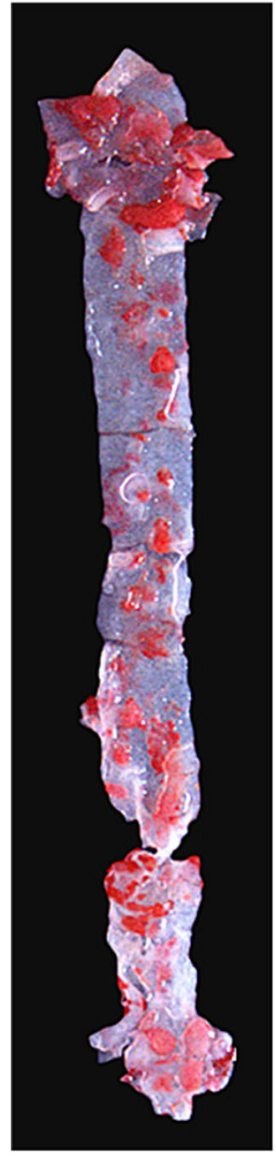

Control

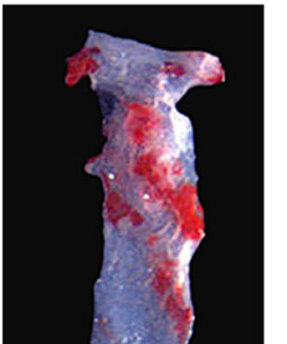

B

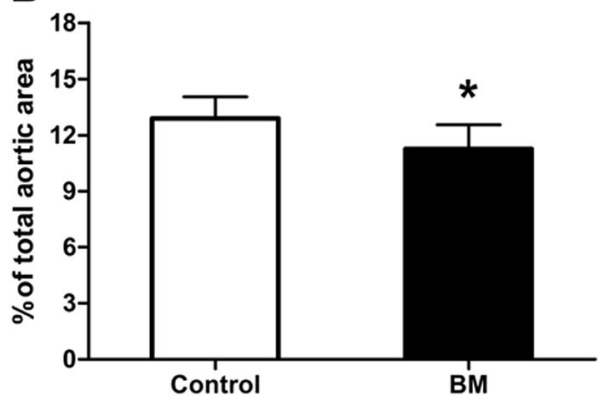

C

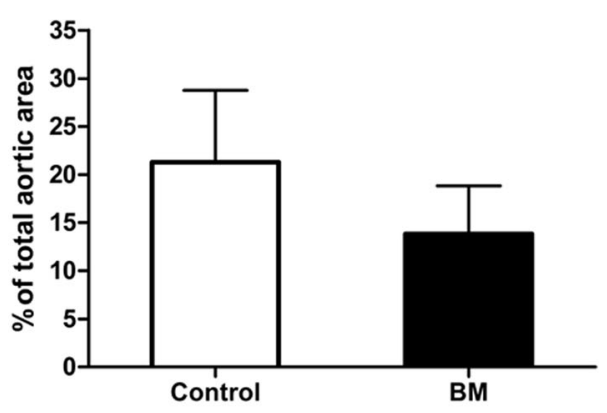

D

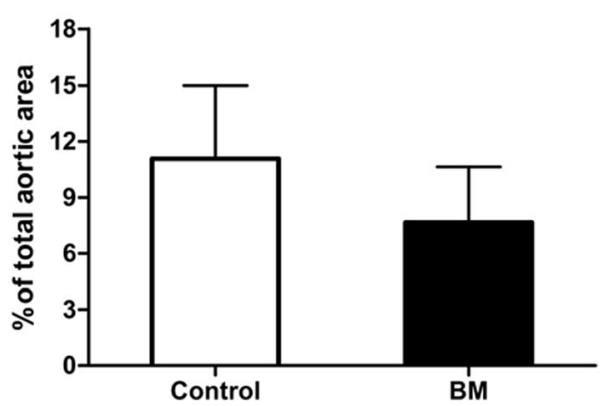

Fig. 3 BM reduced atherosclerotic lesion areas in aortic sections of ApoE-/- mice. a Quantitative analysis of atherosclerotic lesion area was measured on the intimal surface of $(\mathbf{b})$ aorta $(\mathbf{c})$ aortic arch and (d) abdominal aorta of mice in the two groups. Data are mean $\pm S D, n=6$. ${ }^{*} p<0.05$ versus control

\section{Statistical analysis}

All data were expressed as mean \pm SD or mean \pm SEM. Comparisons of means between the two groups were analyzed by un-paired Student's $t$ test. Levene's Test was used for Equality of Variances. A p value $<0.05$ was considered statistically significant. All analysis were performed using SPSS version 13.0 for Windows.

\section{Results}

Effects of BM on body weight, food intake and metabolic profiles

There were no differences between the two groups in body weight at baseline $(18.02 \pm 1.05$ and $18.09 \pm 1.10 \mathrm{~g}$; HFD vs BM; $n=12$ ), but after 16 weeks HFD resulted in a significantly increase of body weight in both groups $(32.73$ \pm 1.43 and $30.95 \pm 1.23$ g; HFD vs BM; $n=12$; Table 1 ).
Compared with the control group, the body weight significantly decreased in BM group from 2 to 16 weeks $(p<0.05$, Fig. 1a). There was no significant difference in food intake and blood glucose levels at 0 , 15, 30, 60 and $120 \mathrm{~min}$ between the two groups (Fig. $1 \mathrm{~b}$ and Fig.2a). BM decreased the serum TG level significantly $(41.04 \pm 11.72$ vs $60.73 \pm 15.62 \mathrm{mg} / \mathrm{dl} ; \mathrm{p}=0.013$; Table 1 and Fig. 2b), while with no effect on TC, LDL ,VLDL and HDL ( $p>0.05$; Table 1 and Fig. 2b).

\section{$\mathrm{BM}$ reduced the area of atherosclerotic lesion in ApoE-/- mice}

The atherosclerotic plaques were showed by Sudan IV staining as Fig. 3a. In ApoE-/- mice fed with HFD, there were fewer atherosclerotic plaques of the entire aorta in $\mathrm{BM}$ group than in control group $(12.91 \pm 1.15$ vs 11.25 

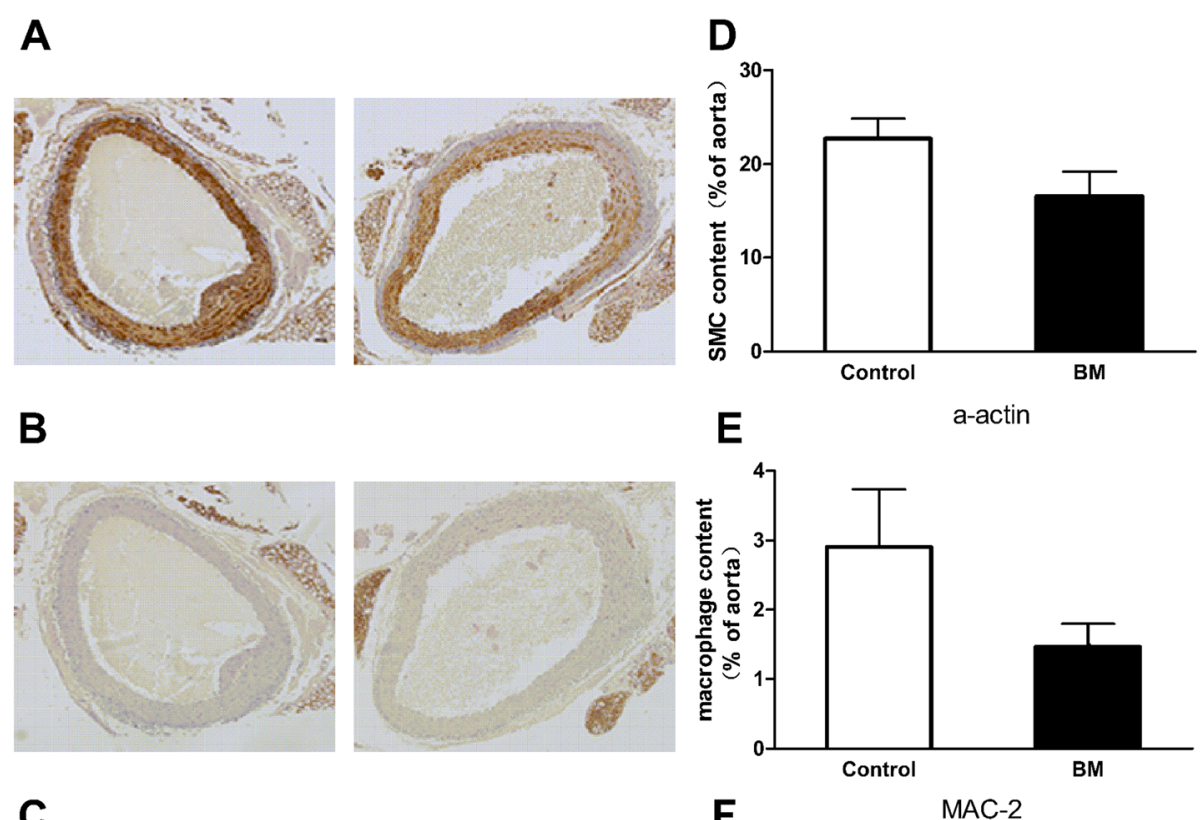

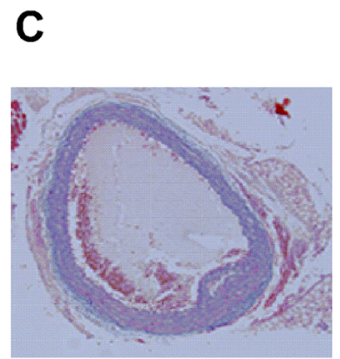

Control

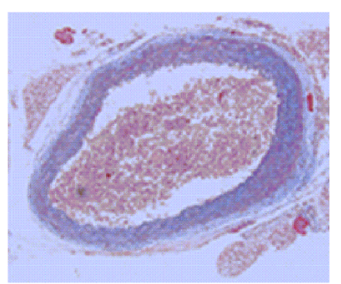

BM

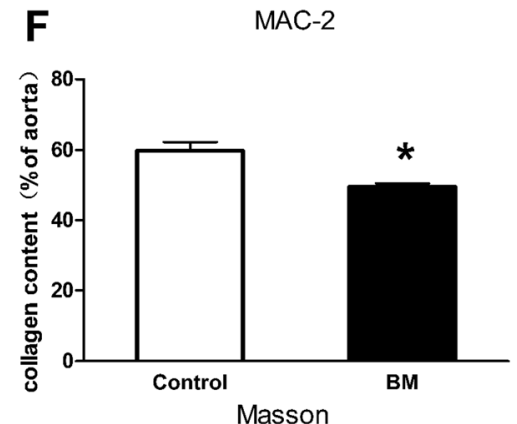

Fig. 4 Effects of BM on expression of a-SMA, MAC-2 and collagen fibers in atherosclerotic plaques. Representative images of smooth muscle cells (a), macrophages (b) and collagen fibers (c) in atherosclerotic plaques ( $n=6$ for each group). Quantitative analysis of smooth muscle cells (d), macrophages (e) and collagen fibers (f) in atherosclerotic area (magnification $\times 100 ; n=6$ for each group). Values are mean \pm SEM; ${ }^{*} p<0.05$; Control vs BM

$\pm 1.31 \%, p=0.042$; Fig. 3b). We found decreasing tendencies exist in the atherosclerotic plaque area of the aortic arch and abdominal aorta under the treatment of BM , although with no statistical significant $(p=0.068$ and $p=0.12$; Fig. 3c, d).

\section{Effects of BM on the histological composition of the atherosclerotic plaques}

The histological composition of atherosclerotic plaques containing vascular smooth muscle cells, macrophages and collagen fibers were analyzed by immunohistochemistry and Masson's trichrome staining (Fig. 4a, b, c). The vascular smooth muscle cells and macrophages expressed in aortic plaques tended to decrease in the BM group compared with the control group, although there was no statistical difference ( $p=0.097$ and $p=0.134$; Fig. $4 \mathrm{~d}, \mathrm{e}$ ). There were significantly less collagen fibers in aortic plaques in BM group than in control group $(49.48 \pm 2.54$ vs 59.83 $\pm 5.82 \mathrm{um}^{2} ; p=0.03$; Fig. 4f).
BM decreased the serum sVCAM-1 and sP-selectin levels and inhibited the expressions of MCP-1 and IL-6 in aortas

The serum levels of adhesion molecules and the expression of inflammatory cytokines in aortas were determined at the end of the study. The serum soluble VCAM-1 and P-selectin significantly decreased in the BM group compared with the control group (1151.92 \pm 142.90 vs $1365.18 \pm 170.26 \mathrm{mg} / \mathrm{dl}, \mathrm{p}=0.008 ; 288 \pm 44.46$ vs $244.43 \pm 46.67 \mathrm{mg} / \mathrm{dl}, p=0047$; Fig. $5 \mathrm{a}, \mathrm{b})$. BM also significantly reduced the expression of MCP-1 and IL- 6 in aorta tissues ( $p=0.002$ and $p=0.048$; Fig. $5 \mathrm{c}, \mathrm{d})$.

\section{Discussion}

In this study, BM was confirmed to reduce the area of atherosclerotic lesion in aortas as well as the content of collagen fibers, smooth muscle cells (SMC) and macrophages in the plaques. Furthermore, we found that BM helps to resist the body weight gain induced by HFD in ApoE-/- mice with no effect on food intake, which is 

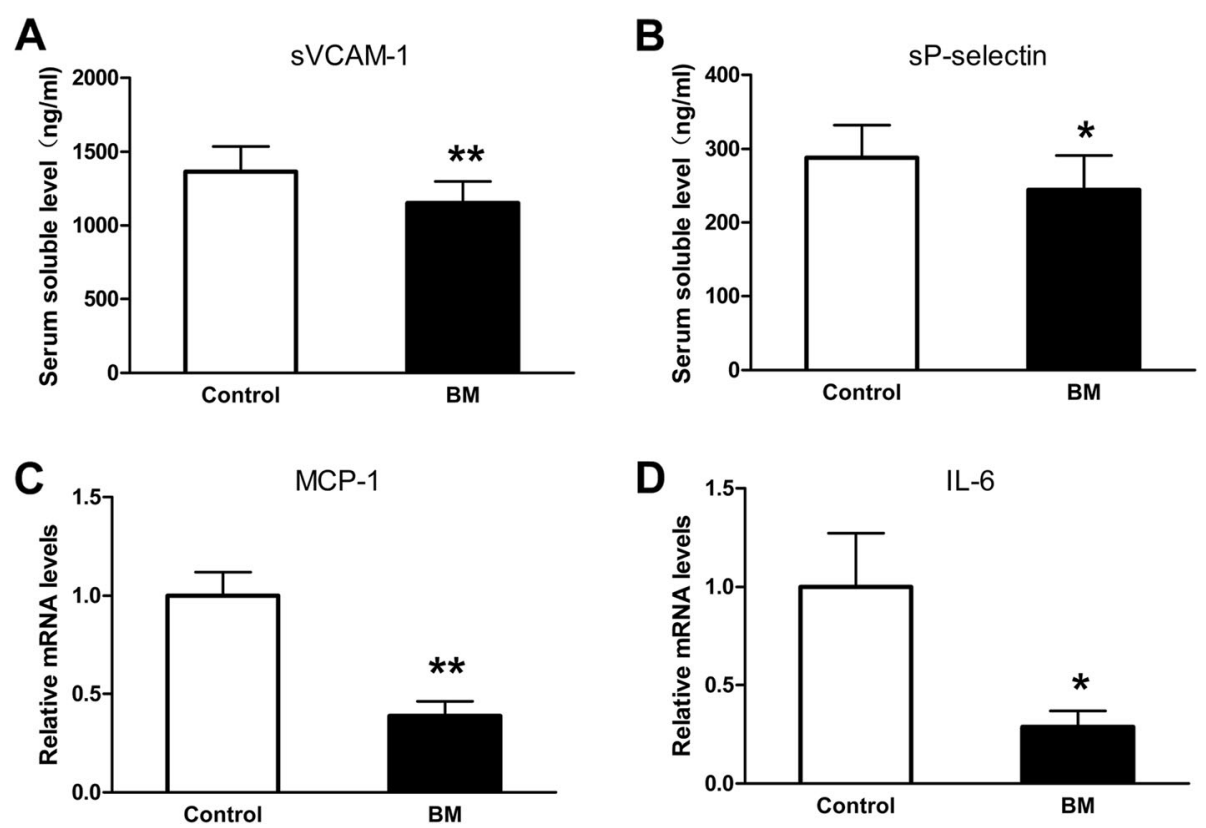

Fig. 5 BM decreased the serum soluble adhesive molecules and the expression of inflammatory cytokines in aortas. a-b Serum concentrations of soluble vascular cell adhesion molecules (VCAM)- 1 and P-selectin ( $n=10$ each). Values are mean \pm SD; $p<0.05,{ }^{* *} p<0.01$; Control vs BM. c-d mRNA expression levels, Monocyte chemotactic protein (MCP)-1 and interleukin (IL)-6 measured in aortas ( $n=6$ each). Values are mean \pm SEM; ${ }^{*} p<0.05$, ${ }^{* *} p<0.01$; Control vs BM

consistent with the previous reports [20]. We observed that the TG, a marker for atherogenic lipoproteins [21], obviously decreased after treating with BM. we also find out the reduction of pro-inflammatory cytokines and cellular adhesion molecules, which play an important role in inflammation of cardiovascular disease, when treated with bitter melon. It has been reported that the concentration of hepatic TG and TC can be decreased by dietary $\mathrm{BM}$ in rats [22-24]. In addition, we observed that serum soluble VCAM-1 and P-selectin levels, which play a major role in the initiation of atherosclerosis, were reduced and the expressions of MCP-1 and IL- 6 in aortas implicated in mediating the pathogenesis of atherosclerosis were decreased by BM treatment [25-27]. Previous researches suggest that there was a strong and independent association between TG and atherosclerosis. Furthermore, triglycerides are an independent predictor of endothelial function which associated with atherosclerosis. It has been reported that raising-triglyceride increase clinical cardiovascular endpoints but lowering circulating triglyceride levels may improve endothelial function, leading to a decrease in cardiovascular events [28-30]. It has been reported that TG may also stimulate atherogenesis by producing proinflammatory cytokines, fibrinogen and coagulation factors. Therefore our data in this study implicated that $\mathrm{BM}$ alleviated the pathogenesis of atherosclerosis possibly through many mechanisms including triglyceridedecreasing, anti-inflammation and endothelial function improvement.

\section{Conclusion}

In summary, our study shows that oral administration of $\mathrm{BM}$ can prevent the progression of atherosclerosis and alter the composition of the atherosclerotic plaques possibly through reducing serum $\mathrm{TG}$ and potential anti-inflammation. These findings suggest that $\mathrm{BM}$ as a nutritional food may plays an important role in CVD protection.

\section{Abbreviations}

AMPK: AMP-Activated protein kinase; ApoE-/-: Apolipoprotein E knock-out; BM: Bitter melon; GPO-PAP: Glycerophosphate oxidase - peroxidase; HDL: High-density lipoprotein cholesterol; HFD: High fat diet; IL-6: Interleukin6; IPGTT: Intraperitoneal glucose tolerance test; LDL: low-density lipoprotein cholesterol; MAC-2: Anti-macrophage-2 antigen; MCP: Monocyte chemoattractant protein; PPAR: Peroxisome proliferator-activated receptor; SOD: Superoxide dismutase; TAS: Total antioxidant status; TC: Total cholesterol; TCM: Traditional chinese medicine; TG: Triglycerides; VCAM: Vascular cell adhesion molecule; VLDL: Very low-density lipoprotein cholesterol; VSMCs: Vascular smooth muscle cells; a-SMA: Anti-alpha-smooth muscle cell

\section{Acknowledgments}

We thank Prof. Yulin Liao at Dept. Cardiology, Nanfang Hospital, Southern Medical University, for providing the technique support.

\section{Funding}

Funding sources are Clinical special research program grant supported by National Natural Science Foundation of China (Grant NO. 81700771) and Free Application Project funded by Guangdong Natural Science Foundation(2017A030313545).

\section{Availability of data and materials}

The datasets supporting the conclusions of this article are included within the article. 


\section{Authors' contributions}

YM Xue, YM Zeng, CZ Li and MP Guan designed the study. YM Zeng performed the experiments. YM Zeng, Lingling Xu,ZJ Zheng and JM Li conducted the animal experiments. YM Zeng and MP Guan analyzed the data and wrote the manuscript. MP Guan and YM Xue supervised the study and revised the manuscript. All authors read and approved the final manuscript.

\section{Ethics approval and consent to participate}

All experiments were following internationally recognized guidelines with the approval of the local council of ethics commitee, according to institutional and government guidelines(certificate number:SCXK2011-0015).

\section{Consent for publication}

All authors declare that they agree to publish this paper.

\section{Competing interests}

The authors declare that they have no conflicts of interest.

\section{Publisher's Note}

Springer Nature remains neutral with regard to jurisdictional claims in published maps and institutional affiliations.

Received: 8 August 2018 Accepted: 21 October 2018

Published online: 06 November 2018

\section{References}

1. Tamar K, Manana A. Involvement of chronic herpesviral infection in intravaskular inflammatory response and destabilisation of current CAD. Atherosclerosis. 2017;263:e115.

2. Burke AC, Huff MW. Regression of atherosclerosis: lessons learned from genetically modified mouse models. Curr Opin Lipidol. 2018;29:87-94.

3. Wang L, Qiu XM, Hao Q, Li D-J. Anti-inflammatory effects of a Chinese herbal medicine in atherosclerosis via estrogen receptor beta mediating nitric oxide production and NF-kappa B suppression in endothelial cells. Cell Death Dis. 2013;4:551-61

4. Poduri A, Rateri DL, Saha SK, Saha S, Daugherty A. Citrullus lanatus 'sentinel' (watermelon) reduces atherosclerosis in LDL receptor-deficient mice. J Nutr Biochem. 2013;24:882-6.

5. Sun GB, Qin M, Ye JX, Pan RL, Meng XB, Wang M, Luo Y, Li ZY, Wang HW, Sun $X B$. Inhibitory effects of myricitrin on oxidative stress-induced endothelial damage and early atherosclerosis in ApoE-/- mice. Toxicol Appl Pharmacol. 2013;271:114-26.

6. Tsai TH, Huang WC, Ying HT, Kuo YH, Shen CC, Lin YK, Tsai PJ. Wild Bitter Melon Leaf Inhibits Porphyromonas gingivalis-Induced Inflammation: Identification of Active Compounds through Bioassay-Guided Isolation. molecules. 2016;21:1-15.

7. Hsueh-Ling CC, YiKuoYun WLC, Lin C. EMCD, a hypoglycemic triterpene isolated from Momordica charantia wild variant, attenuates TNF-a-induced inflammation in FL83B cells in an AMP-activated protein kinaseindependent manner. Eur J Pharmacol. 2012;689:241-8.

8. Nerurkar PV, Johns LM, Buesa LM, Kipyakwai G, Volper E, Sato R, Shah P, Feher D, Williams PG, Nerurkar VR. Momordica charantia (bitter melon) attenuates high-fat diet-associated oxidative stress and neuroinflammation. J Neuroinflamm. 2011:8:64-83.

9. Raish M, Ahmad A, Ansari MA, Alkharfy KM, Aljenoobi Fl, Jan BL, Al-Mohizea AM, Khan A, Ali N. Momordica charantia polysaccharides ameliorate oxidative stress, inflammation, and apoptosis in ethanol-induced gastritis in mucosa through NF-kB signaling pathway inhibition. Int J Biol Macromol. 2018;111:193-9.

10. Tan MJ, Ye JM, Turner N, Hohnen-Behrens C, Ke CQ, Tang CP, Chen T, Weiss HC, Gesing ER, Rowland A, James DE, Ye Y. Antidiabetic activities of triterpenoids isolated from bitter melon associated with activation of the AMPK pathway. Chem Biol. 2008;15:263-73.

11. Sasa M, Inoue I, Shinoda Y, Takahashi S, Seo M, Komoda T, Awata T, Katayama S. Activating Effect of Momordin, of Bitter Melon (Momordica Charantia L.), on the Promoter of Human PPARS. J Atheroscler Thromb. 2009:16:888-92

12. Iseli TJ, Turner N, Zeng XY, Cooney GJ, Kraegen EW, Yao S, Ye Y, James DE, Ye JM. Activation of AMPK by bitter melon triterpenoids involves CaMKKbeta. PLoS ONE. 2013;8:e62309.
13. Cheng HL, Huang HK, Chang Cl, Tsai CP, Chou CH. A Cell-Based Screening dentifies Compounds from the Stem of Momordica charantia that Overcome Insulin Resistance and Activate AMP-Activated Protein Kinase. J Agr Food Chem. 2008;56:6835-43.

14. McCarty MF. Does bitter melon contain an activator of AMP-activated kinase? Med Hypotheses. 2004;63:340-3.

15. Cheng HL, Kuo CY, Liao YW, Lin CC. EMCD, a hypoglycemic triterpene isolated from Momordica charantia wild variant, attenuates TNF-alphainduced inflammation in FL83B cells in an AMP-activated protein kinaseindependent manner. Eur J Pharmacol. 2012;689:241-8.

16. Shih CC, Shlau MT, Lin CH, Wu JB. Momordica charantia Ameliorates Insulin Resistance and Dyslipidemia with Altered Hepatic Glucose Production and Fatty Acid Synthesis and AMPK Phosphorylation in High-fat-fed Mice. Phytother Res. 2013;28:363-71.

17. Zhang Y, Qiu J, Wang X, Zhang Y, Xia M. AMP-Activated Protein Kinase Suppresses Endothelial Cell Inflammation Through Phosphorylation of Transcriptional Coactivator p300. Arterioscler Thromb Vasc Biol. 2011;31: 2897-908.

18. Xu Q, Si L-Y. Protective effects of AMP-activated protein kinase in the cardiovascular system. J Cell Mol Med. 2010;14:2604-13.

19. Tsai TY, Chu LH, Lee CL, Pan TM. Atherosclerosis-preventing activity of lactic acid bacteria-fermented milk-soymilk supplemented with momordica charantia. J Agr Food Chem. 2009;57:2065-71.

20. Wang ZQ, Zhang XH, Yu Y, Poulev A, Ribnicky D, Floyd ZE, Cefalu WT. Bioactives from bitter melon enhance insulin signaling and modulate acyl carnitine content in skeletal muscle in high-fat diet-fed mice. J Nutr Biochem. 2011;22:1064-73

21. Talayero BG, Sacks FM. The role of triglycerides in atherosclerosis. Curr Cardiol Rep. 2011;13:544-52.

22. Chao CY, Sung PJ, Wang WH, Kuo YH. Anti-inflammatory effect of Momordica charantia in sepsis mice. Molecules. 2014;19:12777-88.

23. Ching RH, Yeung LO, Tse IM, Sit WH, Li ET. Supplementation of bitter melon to rats fed a high-fructose diet during gestation and lactation ameliorates fructose-induced dyslipidemia and hepatic oxidative stress in male offspring. J Nutr. 2011:141:1664-72.

24. Senanayake GV, Fukuda N, Nshizono S. Mechanisms underlying decreased hepatic triacylglycerol and Cholesterol by dietary bitter melon in the rat. Lipids. 2012;47:495-503.

25. Ballantyne CM, Entman ML. Soluble Adhesion Molecules and the Search for Biomarkers for Atherosclerosis. Circulation. 2002;106:766-7.

26. Bro S, Moeller F, Andersen CB, Olgaard K, Nielsen LB. Increased Expression of Adhesion Molecules in Uremic Atherosclerosis in Apolipoprotein-EDeficient Mice. J Am Soc Nephrol. 2004;15:1495-503.

27. Shebuski RJ, Kilgore KS. Role of Inflammatory Mediators in Thrombogenesis. J Pharmacol Exp Ther. 2002;300:729-35.

28. Handelsman Y, Shapiro MD. Triglycerides, atherosclerosis, and cardiovascular outcome studies: focus on omega-3 fatty acides. Endocr Pract. 2017;23:100-12.

29. Dron JS, Hegele RA. Genetics of Triglycerides and the Risk of Atherosclerosis. Curr Atheroscler Rep. 2017;19:31.

30. Kajikawa M, Maruhashi T, Matsumoto T. Relationship between serum triglyceride levels and endothelial function in a large community-based study. Atherosclerosis. 2016;249:70-5.

Ready to submit your research? Choose BMC and benefit from:

- fast, convenient online submission

- thorough peer review by experienced researchers in your field

- rapid publication on acceptance

- support for research data, including large and complex data types

- gold Open Access which fosters wider collaboration and increased citations

- maximum visibility for your research: over $100 \mathrm{M}$ website views per year

At BMC, research is always in progress.

Learn more biomedcentral.com/submissions 